\title{
A novel antiapoptotic mechanism based on interference of Fas signaling by CD44 variant isoforms
}

\author{
A Mielgo ${ }^{1}$, M van Driel $^{2}$, A Bloem ${ }^{3}$, L Landmann ${ }^{4}$ and \\ U Günthert ${ }^{\star, 1}$ \\ ${ }^{1}$ Institute of Medical Microbiology, Department of Clinical and Biological \\ Sciences, University of Basel, $\mathrm{CH} 4003$ Basel, Switzerland \\ 2 Department of Internal Medicine, Erasmus Medical Center, Rotterdam NL \\ 3014 GD, The Netherlands \\ ${ }^{3}$ Department of Immunology, University Medical Center, Utrecht NL 3584 CX, \\ The Netherlands \\ ${ }^{4}$ Center of Biomedicine, Department of Clinical and Biological Sciences, \\ University of Basel, CH 4003 Basel, Switzerland \\ * Corresponding author: U Günthert, Institute of Medical Microbiology, \\ Department of Clinical and Biological Sciences (DKBW), University of Basel, \\ Petersplatz 10, Basel CH 4003, Switzerland. Tel: + 41-61-267-3297; \\ Fax: + 41-61-267-3283; E-mail: Ursula.Guenthert@ unibas.ch
}

Received 11.4.05; revised 29.7.05; accepted 01.8.05; published online 16.9.05 Edited by J Tschopp

\begin{abstract}
There is growing evidence that one of the central common characteristics of tumor and inflammatory cells is their resistance to programmed cell death. This feature results in the accumulation of harmful cells, which are mostly refractory to Fas (FAS, APO-1)-mediated apoptosis. A molecule found on these cells is the transmembrane receptor CD44 with its variant isoforms (CD44v). The establishment of transfectants expressing different CD44v isoforms allowed us to demonstrate that the CD44v6 and CD44v9 isoforms exhibit an antiapoptotic effect and can block Fas-mediated apoptosis. Moreover, we observed that CD44v6 and CD44v9 colocalize and interact with Fas. Importantly, an anti-CD44v6 antibody can abolish the antiapoptotic effect of CD44v6. These results are the first to show that CD44v isoforms interfere with Fas signaling. Our findings improve the understanding of the pathogenesis of cancer and autoimmunity and open new strategies to treat such disorders.
\end{abstract}

Cell Death and Differentiation (2006) 13, 465-477.

doi:10.1038/sj.cdd.4401763; published online 16 September 2005

Keywords: CD44v; Fas; cancer; colocalization; resistance to cell death

Abbreviations: DTSSP, (3,3'- Dithiobis-(sulfosuccinimidylpropionate)); EGFP, enhanced green fluorescence protein; FADD, Fas-associating protein with death domain; FasL, Fas ligand; HRP, horseradish peroxidase; IL-6, interleukin-6; $M \beta C D$, methyl-beta cyclodextrin; MMP, matrix metalloproteinase; PARP, poly-ADP ribose polymerase; PFA, paraformaldehyde; $\mathrm{PI}$, propidium iodide; TxR, Texas Red

\section{Introduction}

Since its first sequence description ${ }^{1} \mathrm{CD} 44$ has been attributed an ever-growing list of functions, that can be summarized as outside-in signaling events, conveying information from the cell surface to the nucleus. This multifunctional capacity is in part due to the expression of different CD44 isoforms resulting from alternative splicing that affect and change the extracellular domain of CD44 (reviewed by Günthert ${ }^{2}$ ). Further functional variation has been demonstrated in recent reports, namely that CD44 functions as a coreceptor in multiprotein complexes (reviewed by Ponta et al. ${ }^{3}$ ). The association of CD44 with the integrin VLA-4 abrogates the firm adhesion of cells and increases leukocyte extravasation into sites of inflammation. ${ }^{4}$ Moreover, CD44 variant 6 (CD44v6) forms a multiprotein complex with hepatocyte growth factor (HGF) and its receptor, the tyrosine kinase c-Met, and this interaction is essential for c-Met signaling. ${ }^{5}$ CD44 can act as a specialized platform for matrix metalloproteinases (MMPs), by recruiting MMP9 to the cell surface and thus promoting tumor invasion or MMP7 and ErbB4 to regulate female reproductive organ remodeling. ${ }^{6}$ The interaction of the CD44v6/v7 isoform with the cytokine-like molecule osteopontin promotes inflammation. ${ }^{7}$ In melanoma cells, CD44 can bind the laminin $\alpha 5$ chain which results in inhibition of tumor cell migration, invasion and angiogenesis. ${ }^{8}$

While the standard form of CD44 (CD44s) is ubiquitously expressed, the CD44v isoforms are highly restricted to processes like leukocyte activation, inflammation and malignant transformation (as reviewed by Herrlich et al. ${ }^{9}$ and Wittig et al. ${ }^{10}$ ).

Since it was discovered that the splice variant CD44v4-7 is involved in metastasis of tumor cells, ${ }^{11}$ several studies have addressed the relevance of CD44 variant isoforms as diagnostic and prognostic markers for human tumors (reviewed by Herrlich et al. ${ }^{9}$ and Günthert et al. ${ }^{12}$ ). In multiple myeloma, CD44v9 expression in the absence of CD44v10 on bone marrow plasma cells is associated with a progressive phase of disease, ${ }^{13}$ while CD44v9 expression on bone marrow biopsies of myeloma patients is correlated with an adverse prognosis. ${ }^{14}$ High-grade non-Hodgkin's lymphoma and acute myeloid leukemia express CD44v6 isoforms, indicating a prognostic factor for poor prognosis. ${ }^{15,16}$

Earlier studies have indicated a contribution of CD44 in apoptosis blockade of tumor cells without specifying the involved region and the mechanism implicated. ${ }^{17,18}$

The relevance of $C D 44 v$, but not of $C D 44 s$, in inflammation persistence has also been described (as reviewed by Wittig et al. ${ }^{10}$ and Günthert and Johansson ${ }^{19}$ ). Experimental autoimmune encephalomyelitis and experimental colitis can be efficiently cured by anti-CD44v antibodies. ${ }^{20,21}$ The first evidence that the CD44v region might be involved in apoptosis blockade came from studies with mice lacking CD44v6v7. In contrast to the CD44 wild-type mice, these mice were strongly protected against experimental colitis due to 
increased apoptosis in the inflammatory lesions of the lamina propria. $^{22}$

Control and regulation of alternative splicing is not completely understood. ${ }^{23}$ Expression of CD44v isoforms is under the control of mitogenic signals including the Ras-MAP kinase cascade. ${ }^{24}$ The mechanism(s) through which CD44v isoforms block Fas-mediated apoptosis has so far never been described. Here we show that the presence of CD44v isoforms confers resistance to cell death by interference with Fas, which may have pivotal importance in chronic inflammation and cancer.

\section{Results}

\section{Cells expressing CD44v are resistant to Fas-mediated apoptosis}

To understand the molecular mechanism(s) by which CD44v confers resistance to programmed cell death, we conducted in vitro functional assays using Jurkat cells, which constitutively express Fas, but not CD44. Jurkat cells can easily undergo apoptosis with Fas ligand (FasL) or a Fas crosslinking antibody (clone 7C11). The cells were transfected with cDNA constructs for CD44s (Ju CD44s) and CD44v2-10 (Ju CD44v2-10) (Figure 1a). As a control we used Jurkat cells transfected with the neomycin resistance plasmid alone (Ju neo). The different transfectants were treated with a serial dilution of Fas crosslinking antibody (Figure 1b), or with a constant amount of antibody in a time course, and the amount of apoptotic cells was evaluated by flow cytometry after annexinV/propidium iodide (PI) staining (Figure 1c). We noticed that Jurkat neo (control) and Jurkat CD44s cells quickly underwent apoptosis. Indeed, after $3 \mathrm{~h}$ of treatment with Fas crosslinking antibody we detected about $50 \%$ of apoptotic cells and this number increased to $75 \%$ after $6 \mathrm{~h}$ of induction. However, Jurkat CD44v2-10 cells showed strong resistance to apoptosis and only 5 and $15 \%$ of apoptotic cells were detected after 3 and $6 \mathrm{~h}$ treatment with the Fas crosslinking antibody, respectively. To confirm these results a similar experiment was performed and apoptosis was detected by quantifying cleavage of poly-ADP ribose polymerase (PARP) (Figure 1d and e). We again observed that Jurkat CD44v2-10 cells were more resistant to Fas-mediated cell death than Jurkat CD44s. To confirm that the resistance to apoptosis was due to the presence of CD44v2-10 and not a cloning artifact, transfection was repeated, Jurkat CD44v2-10 (pool II) was generated and the amount of apoptotic cells was determined by measuring hypodiploid DNA (Figure 2a). ${ }^{25}$ No single clones were isolated; these experiments were per- formed with 'pools' of cells expressing similar levels of CD44. Both transfectants, Ju CD44v2-10 (pool I) and Ju CD44v2-10 (pool II) showed similar resistance to cell death. Before using the 'pools', single clones were isolated and selected according to the levels of CD44 expression and, interestingly, those ones with CD44v high expression were more resistant to Fasmediated apoptosis (data not shown). The difference between CD44s and CD44v concerning resistance to cell death was also confirmed by Western blotting (Figure 2b). All the transfectants showed similar levels of Fas and CD44 upon treatment with Fas crosslinking antibody, except for Jurkat neo cells, which were negative for CD44. Additionally, expression of CD44 was also determined by measuring enhanced green fluorescence protein (EGFP) as well as by use of panCD44 and CD44 variant-specific antibodies by flow cytometry (Table 1). When blots were probed with an antiPARP antibody recognizing both the uncleaved $(115 \mathrm{kDa})$ and the cleaved $(85 \mathrm{kDa})$ form, we observed cleavage of PARP after treatment with Fas crosslinking antibody, in Jurkat neo and Jurkat CD44s, indicating that those cells underwent apoptosis. In contrast, extracts from Jurkat CD44v2-10 did not show any cleavage of PARP. These results demonstrate that the function of CD44v isoforms is different from CD44s and that cells expressing CD44v2-10 are significantly more resistant to Fas-mediated apoptosis. We did not observe any variation in the expression levels of Fas, CD44, Fasassociating protein with death domain (FADD) and $\mathrm{Bcl}-2$ in the different transfectants upon treatment with Fas crosslinking antibody. When cells were treated with UV light, heat shock, PMA/ionomycin or $\gamma$-irradiation, CD44s and CD44v210 Jurkat cells showed similar sensitivity to cell death and with higher doses of $\gamma$-irradiation, Ju CD44v2-10 were even more susceptible to apoptosis. These results indicate that CD44v210 does not protect the cells from other forms of cell death beside Fas-mediated apoptosis (Figure 2c).

\section{CD44v6 and v9 are sufficient for mediating resistance to apoptosis}

To address which is/are the variant regions responsible for the resistance to programmed cell death we used Jurkat transfectants expressing the variant regions 6-10 (Ju CD44v6-10), only variant 3 (Ju CD44v3), variant 6 (Ju CD44v6) or variant 9 (Ju CD44v9) within the context of the standard backbone. To directly examine the behavior of the different variant regions, the different transfectants were treated with FasL for $6 \mathrm{~h}$ and apoptosis was measured by determining hypodiploid DNA. Only cells expressing the

Figure 1 Jurkat CD44v2-10 cells but not Jurkat CD44s cells are protected from Fas-mediated apoptosis. (a) Scheme of the different CD44-EGFP constructs used for transfection of Jurkat and XG-1 cells. (b) Jurkat neo (negative control), Jurkat CD44s, Jurkat CD44v2-10 cells were treated with a serial dilution (10-200 ng/ml) of Fas crosslinking antibody (clone $7 \mathrm{C} 11$ ) for $6 \mathrm{~h}$. Subsequently, the percentage of apoptotic cells was determined by flow cytometry with annexinV/PI staining and was calculated by subtracting the control values from the values obtained with 7C11 treatment. Values are given for one experiment representative of three. (c) Jurkat neo, Jurkat CD44s, Jurkat CD44v2-10 cells were treated with Fas crosslinking antibody for 1,3 or $6 \mathrm{~h}$. Apoptotic cells were determined with annexinV/PI staining. Values are given for one experiment representative of three. (d) Jurkat transfectants were treated with recombinant FasL and the percentage of apoptotic cells was determined by flow cytometry with a fluorescently labeled antibody recognizing the cleaved form of PARP, p85 PARP. Data are representative of three independent experiments. (e) FACS analysis of Jurkat neo, Jurkat CD44s and Jurkat CD44v2-10 untreated and treated with Fas crosslinking antibody. Percentage of p85 PARP-positive cells was evaluated by flow cytometry with an anti-p85 PARP PE-labeled antibody. The bar is limiting the living cells on the left according to the control. Numbers in the upper right corner represent the percentage of apoptotic cells 
a

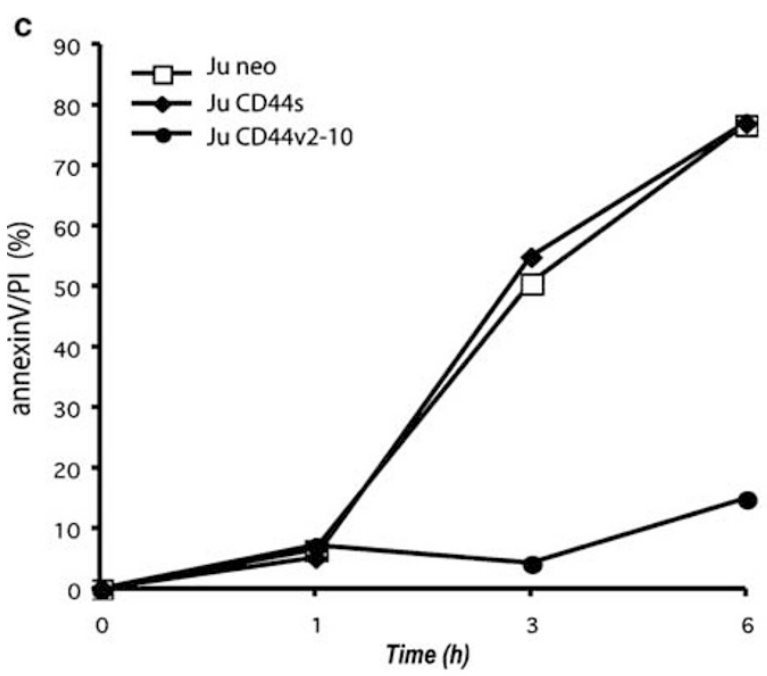

CD44s/EGFP

CD44V6/EGFP

CD44V9/EGFP

CD44v8-10/EGFP b
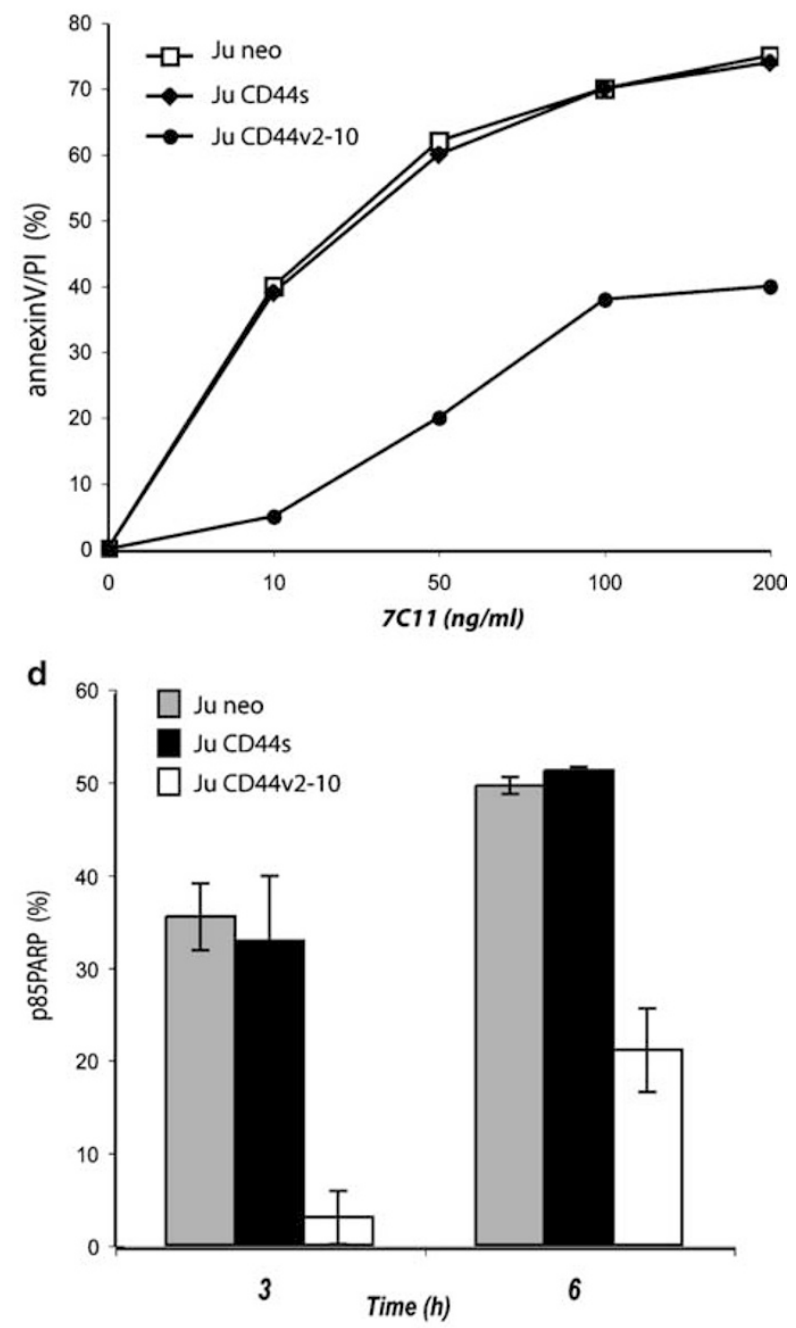

e
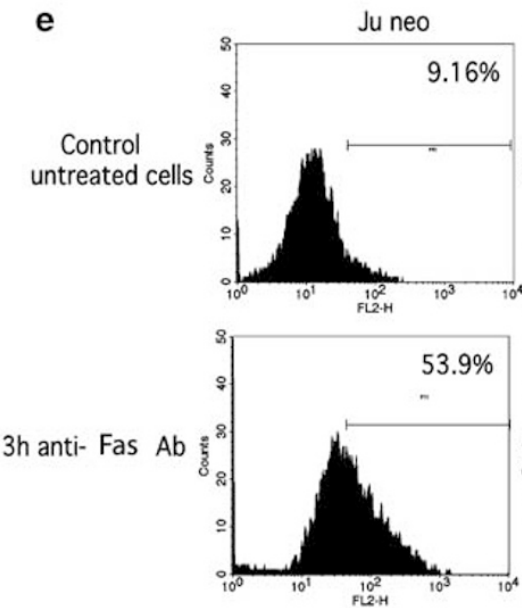

d

CD44V2-10/EGFP
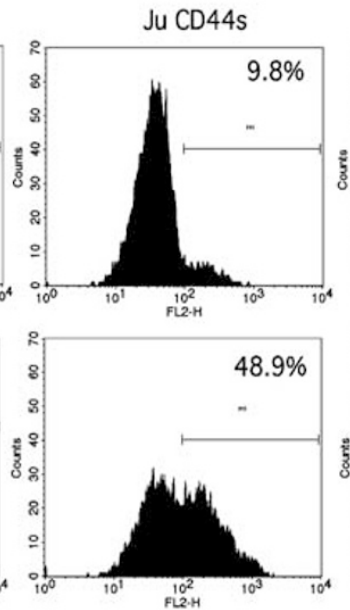

p85 PARP
Ju CD44v2-10
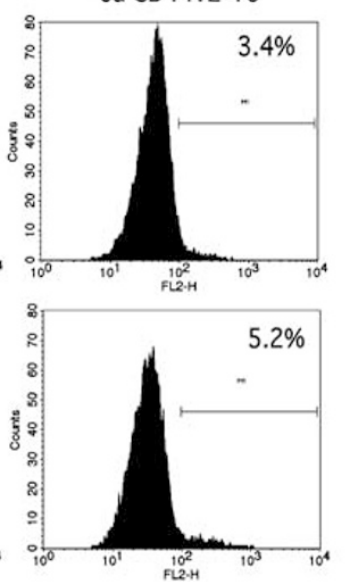
a

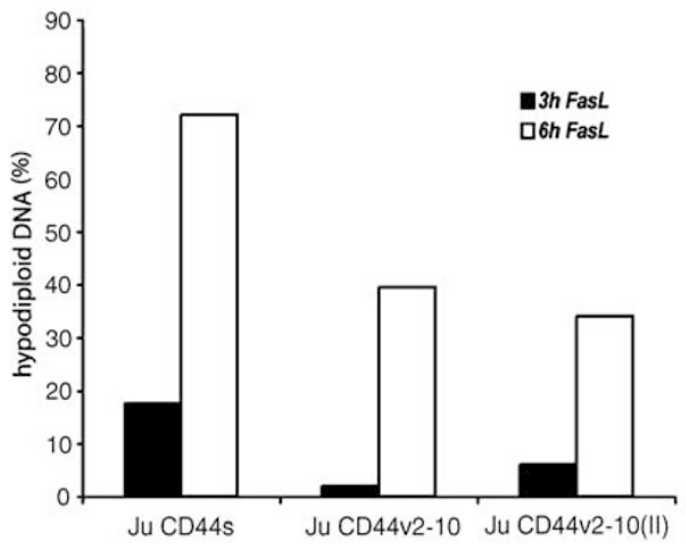

C

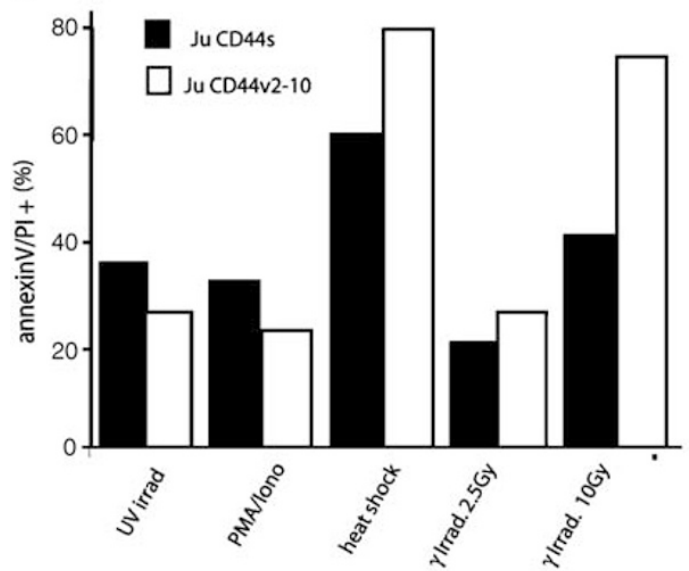

b

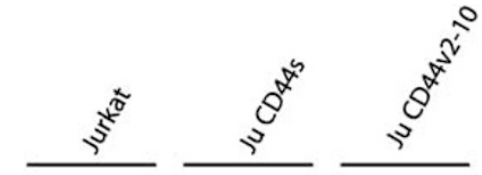

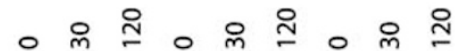

$120 \mathrm{kDa}$

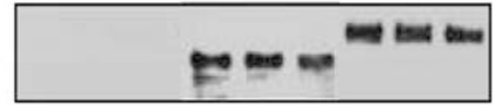

CD44

$45 \mathrm{kDa}$

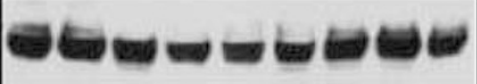

Fas

$115 \mathrm{kDa}$

$85 \mathrm{kDa}$

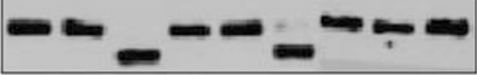

PARP

$24 \mathrm{kDa}$

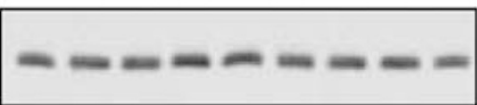

FADD

$26 \mathrm{kDa}$

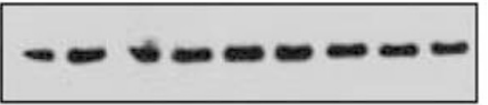

$\mathrm{BCl}-2$

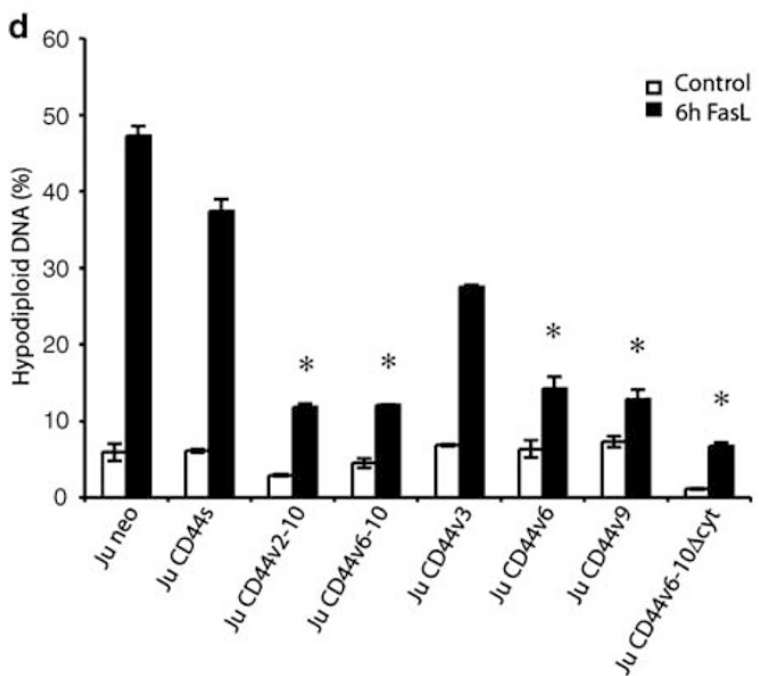

Figure 2 CD44v6 and v9 are sufficient for mediating resistance to Fas-mediated apoptosis in Jurkat cells. (a) A second independent Jurkat CD44v2-10 (pool II) transfectant was established, induced with FasL and the amount of apoptotic cells was determined by measuring hypodiploid DNA by flow cytometry (hypodiploid $\mathrm{DNA}=$ subG1 apoptotic population). Values are given for one experiment representative of three. (b) After treatment with $7 \mathrm{C} 11$ for 30 or 120 min, cells were collected, lysed in Ripa buffer and Western blotted with anti-panCD44, anti-Fas, anti-PARP antibody recognizing both, the uncleaved and the cleaved form of PARP, anti-FADD and anti-Bcl-2 antibodies. (c) Jurkat CD44s and Jurkat CD44v2-10 were induced to undergo cell death with UV light, PMA/lonomycin, heat shock, or $\gamma$ irradiation. The amount of apoptotic cells was evaluated with annexinV/PI staining by flow cytometry. Values are given for one experiment representative of three. (d) Jurkat neo, Jurkat CD44s, Jurkat CD44v2-10, Jurkat CD44v6-10, Jurkat CD44v3, Jurkat CD44v6, Jurkat CD44v9 and Jurkat CD44v6-10 $\Delta$ cyt cells were treated with FasL for $6 \mathrm{~h}$ and the percentage of apoptotic cells was determined by measuring hypodiploid DNA (hypodiploid DNA = subG1 apoptotic population). Data are representative of five independent experiments and were analyzed with the Wilcoxon signed-rank test $\left(^{*}, P<0.05\right)$

variant regions 6 and/or the variant 9 were significantly more resistant to Fas-mediated apoptosis (Figure 2d) than CD44stransfected cells. The Ju CD44v3 was slightly more resistant to apoptosis compared to Ju CD44s. Nevertheless, this difference was not statistically relevant. This suggests that the resistance to apoptosis observed in the variant positive cells is not due to the proliferation stimulus caused by growth factors binding to the heparan sulfate chains located at the variant 3 region. $^{26}$ Moreover, Jurkat cells expressing CD44v6-10 (or CD44v2-10, not shown), but lacking the cytoplasmic domain were also strongly protected from cell death. This observation clearly points out the significance of the extracellular domain of CD44v for apoptosis resistance (Figure 2d).

Previous analyses demonstrated a significant correlation between CD44v9 expression and a poor prognosis for patients with multiple myeloma. ${ }^{13,14}$ To investigate a possible relationship between CD44v expression and apoptosis resistance with more potential clinical relevance, we chose plasmacytoma cell lines and an EBV-positive lymphoblastoma 
Table 1 Expression of CD44 isoforms and Fas in cell transfectants

\begin{tabular}{|c|c|c|c|c|c|c|c|}
\hline Cell lines & pan CD44 & $\begin{array}{c}\text { CD44 } \\
\text { v3 }\end{array}$ & $\begin{array}{c}\text { CD44 } \\
\text { v6 }\end{array}$ & $\begin{array}{c}\text { CD44 } \\
\text { v7 }\end{array}$ & $\begin{array}{c}\text { CD44 } \\
\text { v9 }\end{array}$ & $\begin{array}{c}\text { CD44 } \\
\text { v10 }\end{array}$ & Fas \\
\hline RPMI-8226 & - & - & - & - & - & - & + \\
\hline IM-9 & + & - & - & - & - & - & + \\
\hline U266 & + & + & - & - & + & - & + \\
\hline $\mathrm{NCl}-\mathrm{H} 929$ & + & + & - & - & + & - & + \\
\hline$X G-1^{+}$ & + & + & + & - & + & - & + \\
\hline$X G-1^{-}$ & + & - & - & - & - & - & + \\
\hline XG-1 neo & + & - & - & - & - & - & + \\
\hline$X G-1$ v6 & + & - & + & _- & - & - & + \\
\hline$X G-1$ v9 & + & - & - & - & + & - & + \\
\hline Ju neo & - & - & - & - & - & - & + \\
\hline Ju CD44s & + & - & - & - & - & - & + \\
\hline Ju CD44v2-10 & - & + & + & + & + & + & + \\
\hline Ju CD44v6-10 & - & - & + & + & + & + & + \\
\hline Ju CD44v3 & - & + & - & - & - & - & + \\
\hline Ju CD44v6 & - & - & + & - & - & - & + \\
\hline Ju CD44v9 & - & - & - & - & + & - & + \\
\hline
\end{tabular}

Expression of CD44s, v3, v6, v7, v9, v10 and Fas on plasmacytoma cell lines and an EBV-positive lymphoblastoma cell line, CD44-transfected XG-1 plasmacytoma cell lines and CD44-transfected Jurkat (Ju) cell lines, measured by FACS. Plasmacytoma cell lines U266 and XG- $1^{+}$are IL- 6 dependent.

cell line from a multiple myeloma patient. The latter cell lines were assayed for their susceptibility to Fas-mediated apoptosis and correlation to CD44v9 expression. CD44 and Fas expression levels of five plasmacytoma cell lines and the IM9 cell line analyzed by flow cytometry are listed in Table 1. When different cell lines were induced to undergo apoptosis, we observed that $\mathrm{CD} 44 \mathrm{v} 9^{+}$cells were clearly more resistant to apoptosis than cells lacking v9 expression (Figure 3a). XG-1 was selected as an interleukin-6 (II-6) independently growing variant of $\mathrm{XG}-1^{+}$. Compared to $\mathrm{XG}-1^{+}, \mathrm{XG}-1^{-}$had lost the expression of CD44v3, v6 and $v 9$, but still expressed CD44s. To substantiate these observations, the XG-1 ${ }^{-}$cells were transfected with CD44v6, CD44v9, CD44v10, CD44v810 and CD44v3-10 constructs. The different transfectants were treated with the Fas crosslinking antibody and apoptosis was measured by detection of active caspase 3 (Figure 3b). We observed that all XG-1 cells expressing the CD44v9 region were resistant to cell death induction. For unknown reasons the XG-1 neo cells showed especially high levels of caspase 3 activity compared with XG-1v6 and XG-1v10. Nevertheless, caspase 3 activity in XG-1v6 and v10 was at least 2.5-3 times higher than in XG-1v9. Further the cells were treated with Fas crosslinking antibody and apoptosis was measured by detecting PARP cleavage by flow cytometry (Figure $3 c$ ) or by annexinV/PI staining (Figure $3 d$ ). We again observed that only the cells expressing CD44v9 showed lower levels of p85 PARP and annexinV/PI staining. In this system, the expression of CD44v9 could protect the cells from undergoing cell death whereas the expression of CD44v6 or CD44v10 did not give such a protection. This difference concerning apoptosis resistance conferred by CD44v6 in Jurkat, but not in XG-1 cells could be due to post-translational modifications (e.g. alterations in glycosylation) that are celltype and growth-condition specific. These data demonstrate that the CD44v6 and 9 regions, depending on the cell type, can play essential roles in preventing the cells from undergoing programmed cell death.

\section{Colocalization of CD44v and Fas}

We have shown that Jurkat and XG-1 cells expressing CD44v6 and/or v9 are strongly protected from Fas-mediated apoptosis. Consequently, we were interested in understanding the molecular mechanism(s) of protection. Therefore, we explored by confocal microscopy if CD44 and Fas colocalize. The results showed that CD44v2-10, CD44v6 and CD44v9 strongly colocalized with Fas (Figure 4b, c, d), whereas colocalization between CD44s and Fas was significantly less intense (Figure 4a). To quantify the percentage of colocalization, confocal image stacks were recorded and analyzed with the Imaris software. In cells not induced to undergo apoptosis, the percentage of colocalization between Fas and CD44v was significantly higher (36\%) than between Fas and CD44s (13\%) (Figure $4 \mathrm{e}$ ). When the cells were treated with the Fas crosslinking antibody or with FasL, the colocalization between CD44v and Fas strongly increased and was also significantly higher than the colocalization observed between CD44s and Fas. The increase in colocalization observed when the cells were induced to undergo Fas-mediated apoptosis appeared to be unspecific as it increased in similar rates for CD44s and CD44v. However, irrespective of presence or absence of Fas apoptosis inducers, the colocalization between CD44v and Fas was always significantly stronger compared to CD44s. These results strongly suggest a possible molecular interaction between CD44v and Fas.

\section{Cells expressing CD44s or CD44v show reduced Fas-mediated apoptosis after disruption of lipid rafts}

CD44 and Fas have both been described to be recruited into lipid rafts. ${ }^{27,28}$ To understand the relevance of this reaction for CD44 and Fas colocalization during apoptosis induction in vitro, we performed functional assays using the Jurkat CD44s and CD44v2-10 transfected cells. Both transfectants were treated with methyl-beta cyclodextrin ( $M \beta C D)$, followed by treatment with FasL. Controls of untreated cells and cells treated only with FasL were performed. The amount of apoptotic cells was determined by measuring hypodiploid DNA by flow cytometry ${ }^{25}$ (Figure $5 a$ ). We could again observe that after induction of apoptosis with FasL, cells expressing CD44v2-10 were significantly more resistant to apoptosis than cells expressing the CD44s isoform. Furthermore, we observed that treatment with $\mathrm{M} \beta \mathrm{CD}$ (a disrupter of lipid rafts) caused a significant reduction of hypodiploid DNA in both transfectants (37 to $12-10 \%$ for the Ju CD44s and 12 to $6-7 \%$ for the Ju CD44v2-10). These results support the notion that integrity of lipid rafts is required for Fas-mediated apoptosis, irrespective of whether the cells express CD44s or CD44v.

\section{The CD44 variant region interacts with Fas}

To find out whether a physical association exists between CD44v and Fas, we performed co-immunoprecipitations using the nitrogen cavitation bomb method. This is an alternative procedure to the standard co-immunoprecipitations for examining interactions between membrane proteins. ${ }^{29}$ The advantage of this procedure is that it is detergent 

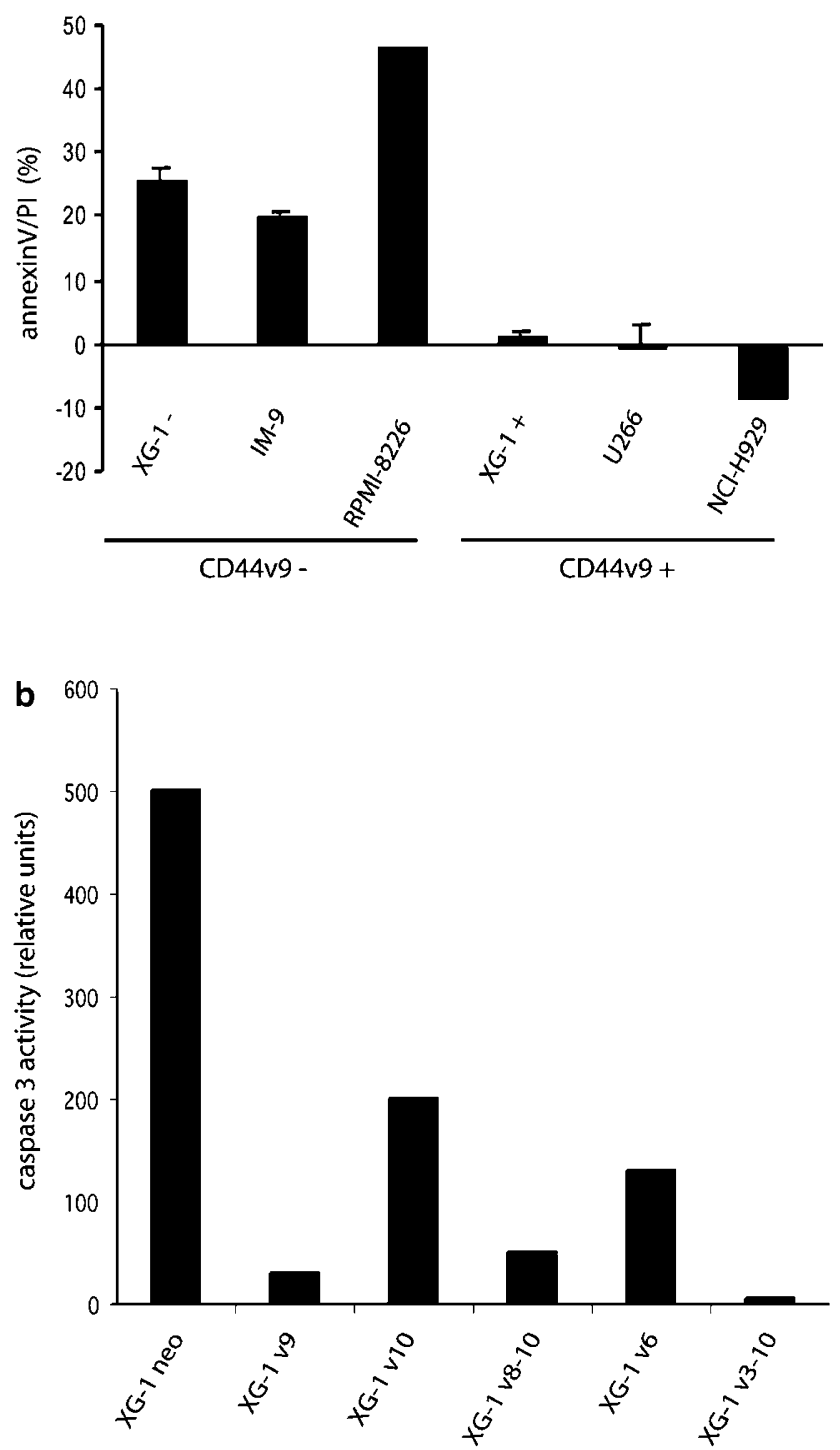

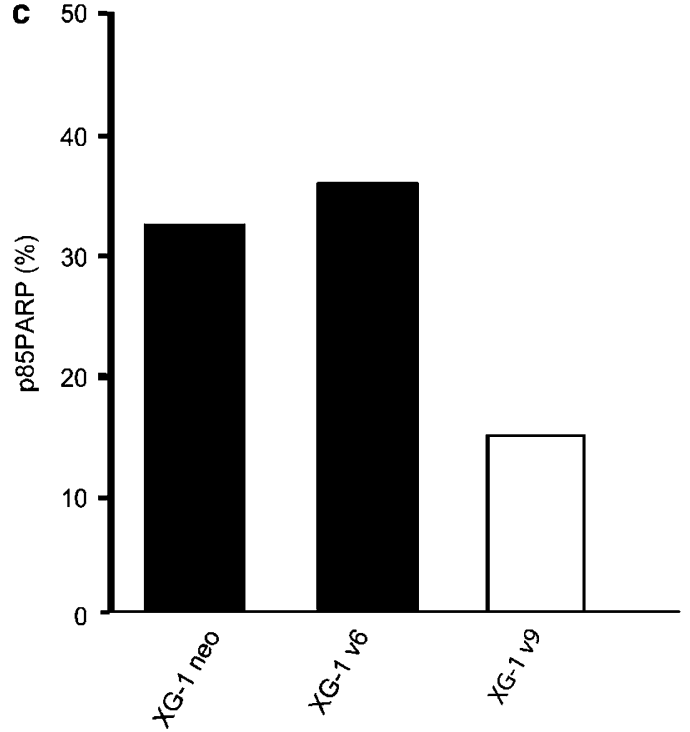

d

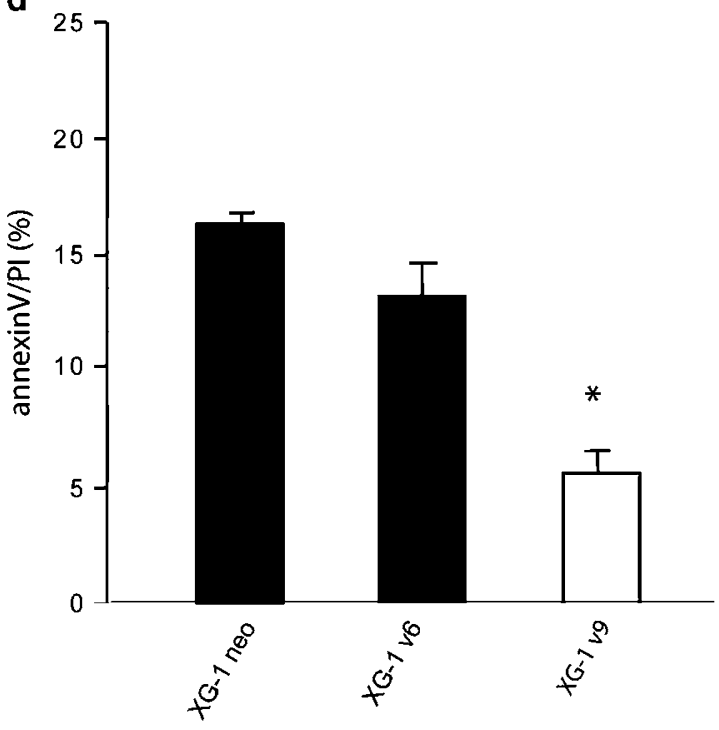

Figure 3 CD44v9 is sufficient for mediating resistance to Fas-mediated apoptosis in XG-1 plasmacytoma cells. (a) Plasmacytoma cell lines XG-1-, RPMI-8226, $\mathrm{XG}-1^{+}, \mathrm{U} 266$ and $\mathrm{NCl}-\mathrm{H} 929$ and the EBV ${ }^{+}$lymphoblastoma cell line IM9, were treated for $24 \mathrm{~h}$ with the Fas crosslinking antibody (7C11) or with control mouse lgM. Apoptosis was determined by annexinV/PI staining. Values are representative of three independent experiments. (b) XG- $1^{-}$transfectants were incubated for $24 \mathrm{~h}$ with the Fas crosslinking antibody (7C11) or control IgM and the percentage of apoptotic cells was detected by measuring active caspase-3. Values are given for one experiment representative of three. (C) XG-1 ${ }^{-}$transfectants were treated with $7 \mathrm{C} 11$ or control lgM for $24 \mathrm{~h}$ and the percentage of apoptotic cells was determined by flow cytometry with a fluorescently labeled antibody recognizing the cleaved form of PARP. Values are given for one experiment representative of three. (d) XG-1 transfectants were incubated for $24 \mathrm{~h}$ with $7 \mathrm{C} 11$ or control lgM and the percentage of apoptotic cells was detected by measuring annexinV/PI-positive cells. Data are representative of three independent experiments and were analyzed with a two-sided unpaired Student's $t$-test $\left({ }^{*}, P<0.05\right)$. The percentage of apoptotic cells was calculated by subtracting the control values (IgM treatment) from the values obtained with anti-Fas treatment

free and therefore highly suitable to study interactions between membrane proteins, which can be recruited into lipid rafts and are very difficult to extract with conventional lysis buffers without destroying the natural interactions existing between the candidate molecules. To examine the association between CD44 and Fas, we first used nitrogen cavitation bomb extractions targeting CD44 (CD44 antibodydecorated cavitation bomb extractions) from Jurkat neo, Jurkat CD44s and Jurkat CD44v2-10 cells and performed Western blotting detection with anti-Fas antibody. Before extraction, the samples were surface crosslinked with $3,3^{\prime}$ Dithiobis-(sulfosuccinimidylpropionate) (DTSSP) (crosslinker cleavable under reducing conditions). Only anti-CD44 extractions from Jurkat CD44v2-10 cells probed with anti-Fas antibody gave rise under reducing conditions to a strong $45 \mathrm{kDa}$ band corresponding to Fas (Figure 5b). When cavitation bomb extractions were performed without crosslinker, we observed similar results, but the $45 \mathrm{kDa}$ band was less intense (data not shown). To confirm these results, Western blotting for CD44 of nitrogen cavitation bomb 


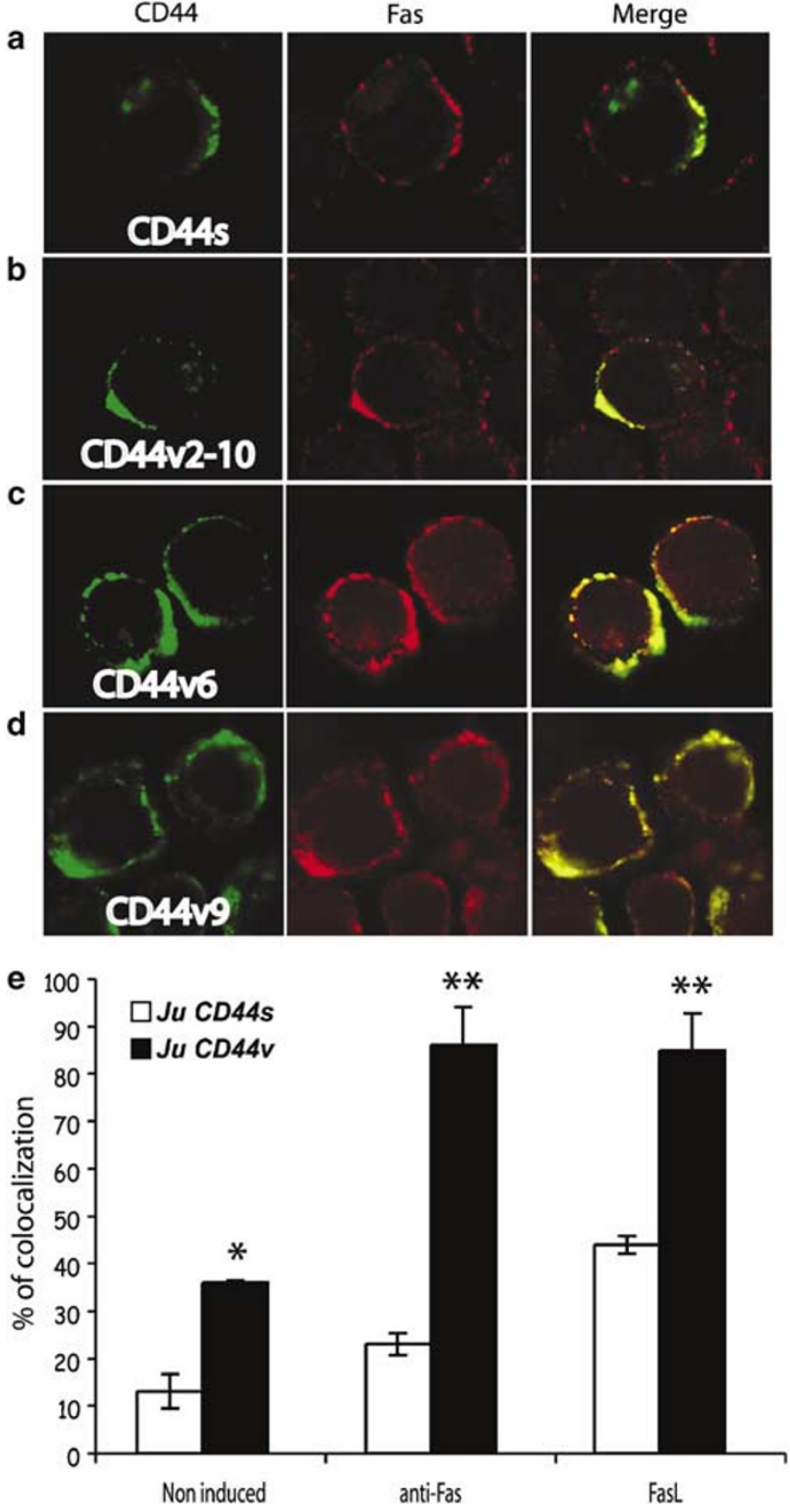

Figure 4 The CD44 variant region and Fas specifically colocalize. Jurkat cells transfected with CD44s (a), CD44v2-10 (b), CD44v6 (c) and CD44v9 (d) were treated for $1 \mathrm{~h}$ with FasL and then stained with the anti-panCD44 antibody Hermes-3, followed by Cy2-labeled goat anti-mouse antibody (green fluorescence) and with an anti-Fas biotinylated antibody, followed by SA-TxR. (e) Histogram representing the percentages of CD44 and Fas colocalization under non-apoptosis-inducing conditions, induced with Fas crosslinking antibody (clone $7 \mathrm{C11}$ ) and induced with FasL. White bars represent the percentage of colocalization between CD44s and Fas, black bars the percentage of colocalization between CD44v and Fas. Data are representative of five independent experiments and were analyzed with the Wilcoxon signed-rank test $\left({ }^{*}, P<0.05 ;{ }^{* *}, P<0,01\right)$

extractions targeting Fas (Fas-decorated cavitation bomb extractions) from the different transfectants was performed. This experiment was reproduced under two conditions: cells untreated (Figure $5 \mathrm{c}$, upper panel) and cells treated with FasL (Figure $5 c$, lower panel). In the untreated cells we detected a strong band at $140 \mathrm{kDa}$, corresponding to CD44 fused to EGFP, in the extracts obtained from Jurkat CD44v6 and Jurkat CD44v9-transfected cells (upper panel). A weaker band appeared in the extracts from Jurkat CD44v3. No bands were observed in the extracts from the control Jurkat neo cells or Jurkat CD44s-transfected cells. When the cells were treated with FasL, similar results were observed: no bands for Jurkat neo and Jurkat CD44s, a strong band at $140 \mathrm{kDa}$ for Jurkat CD44v6 and v9 and a weaker band for Jurkat CD44v3 extracts (lower panel). Western blotting was also performed under nonreducing conditions and high molecular aggregates around $250 \mathrm{kDa}$ in the Ju CD44v were observed (data not shown). This $250 \mathrm{kDa}$ band most likely corresponds to one molecule of CD44v2-10 (composed of about $170 \mathrm{kDa}$ for CD44v2-10 and $30 \mathrm{kDa}$ for GFP) and one Fas monomer (45 kDa). Equal expression of CD44 and Fas was confirmed by Western blotting in all the transfectants (Figure $5 \mathrm{~d}$ ). These data confirm that only CD44v, but not CD44s, interacted with Fas and that CD44v6 and v9 strongly interacted with Fas, whereas CD44v3 did so at lesser intensity.

\section{Blocking the variant 6 region of CD44 restores the apoptotic potential}

We have demonstrated that CD44v-positive cells were more resistant to Fas-mediated apoptosis and that CD44v colocalizes and interacts physically with Fas. With the knowledge that resistance to Fas-mediated apoptosis is a major caveat for treatment of tumor cells and cells in chronic inflammatory lesions, we were interested in preventing the interaction of CD44v/Fas and therefore make the cells susceptible to Fasmediated cell death. For this purpose we tried to block the variant region of CD44 with different antibodies. Blocking the CD44v6 region with anti-CD44v6 antibodies (clones VFF18 and BBA13) successfully worked in Jurkat cells. However, the anti-v9 antibody (clone FW11.24) was unable to block the CD44v9 region, neither in Jurkat nor in XG-1 cells. This antibody could be used for FACS staining of the cells, but is not functioning as a blocking antibody. Jurkat CD44s, Jurkat CD44v6 and Jurkat CD44v6-10-transfected cells were incubated with anti-CD44v6 antibody (BBA 13), followed by apoptosis induction with FasL and determining PARP cleavage (Figure 6a). When cells were only treated with FasL we observed that $47.4 \%$ of cells were apoptotic in the Jurkat CD44s sample and only 5.5 and 6\% in Jurkat CD44v6 and Jurkat CD44v6-10, respectively (Figure 6a middle panels). When cells were preincubated with BBA13 and then induced with FasL, the percentage of apoptotic cells in the Jurkat CD44v6 and the Jurkat CD44v6-10 samples significantly increased to 37.7 and $42.5 \%$, respectively, whereas the apoptotic ratio for the Jurkat CD44s was unchanged (lower panels). When in a similar set-up apoptosis was measured by determining hypodiploid DNA, we obtained equivalent data (Figure 6b). In addition, we observed that the anti-v6 antibody did not have any sensitization effect on Jurkat CD44v9 (Figure 6b). These data confirm v6 as one of the variant regions involved in preventing Fas-mediated apoptosis and that it is possible to regain susceptibility to apoptosis by blocking specifically the v6 region of CD44. 
a

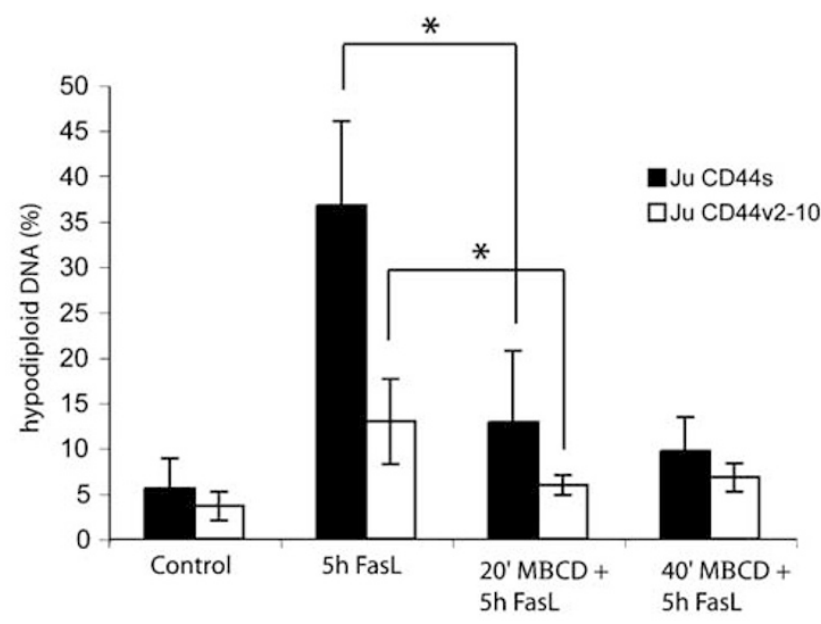

b

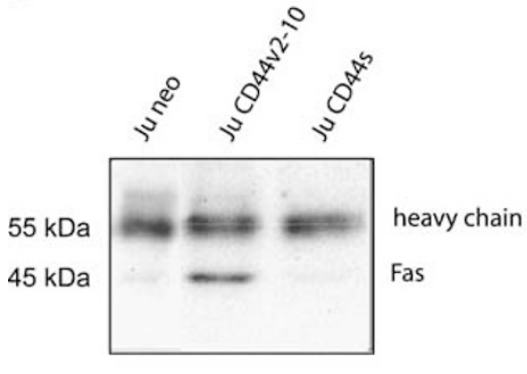

C

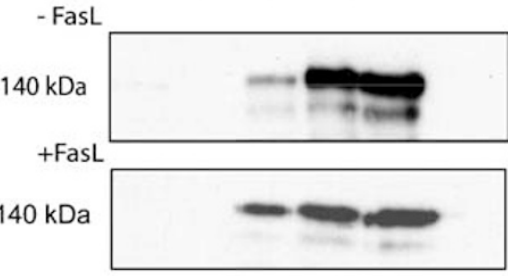

CD44

CD44

d

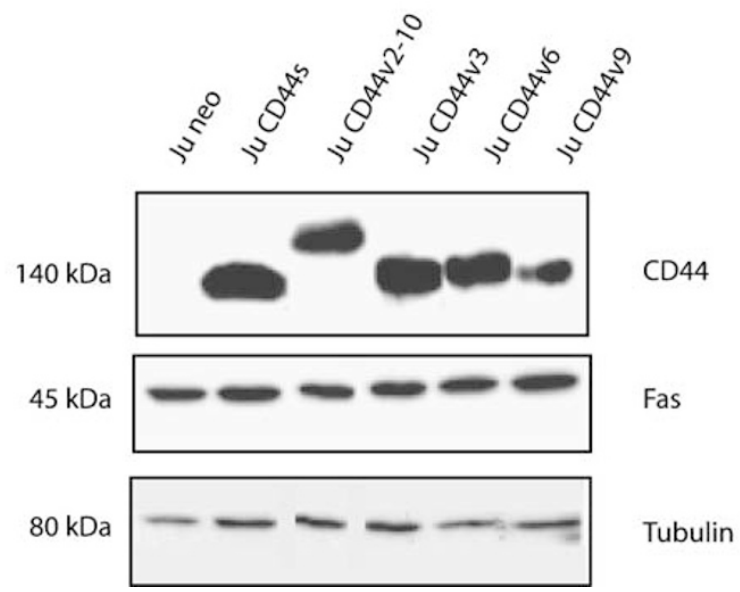

Figure 5 Interaction between Fas and CD44v isoforms in lipid rafts. (a) Jurkat CD44s and Jurkat CD44v2-10 cells were pretreated for 20 or 40 min with M $\beta C D$, then induced with FasL for $5 \mathrm{~h}$. Subsequently, the percentage of apoptotic cells was determined by measuring hypodiploid DNA (hypodiploid DNA= subG1 apoptotic population). Data are representative of three independent experiments. (b) Western blotting for Fas on CD44 cavitation bomb extractions from Jurkat neo, Jurkat CD44v2-10 and Jurkat CD44s cells. Cells were incubated with magnetic beads coated with mouse anti-human CD44, treated for 10 min with FasL, before nitrogen cavitation bomb extraction. Then, 10\% SDS-PAGE was performed under reducing conditions, followed by Western blotting with polyclonal rabbit anti-Fas antibody and HRP-conjugated goat anti-rabbit secondary antibody. (c) Upper panel: Western blotting for panCD44 on Fas cavitation bomb extractions from Jurkat neo, Jurkat CD44s, Jurkat CD44v3, Jurkat CD44v6, Jurkat CD44v9 cells. Cells were incubated with magnetic beads coated with mouse anti-human Fas antibodies before nitrogen cavitation bomb extraction. Then, 10\% SDS-PAGE was performed under reducing conditions followed by Western blotting with mouse anti-human CD44 antibody and HRPconjugated goat anti mouse secondary antibody. Lower panel: An equivalent experiment, as shown in the upper panel, was performed with cells treated with FasL for 10 min. (d) Western blotting for CD44 and Fas on total cell extractions from Jurkat neo, Jurkat CD44s, Jurkat CD44v2-10, Jurkat CD44v3, Jurkat CD44v6 and Jurkat CD44v9 cells. Extractions were performed with RIPA buffer and the lysates were run in a 10\% SDS-PAGE under reducing conditions. Western blotting was performed with mouse anti-human CD44 antibody followed by HRP-conjugated goat anti-mouse secondary antibody or anti-human Fas antibody followed by HRP-conjugated goat anti-rabbit secondary antibody. Tubulin was used as a loading control

\section{Discussion}

Programmed cell death is not only essential for normal development and regeneration, but also to eliminate cells that represent a threat to the integrity of the organism. Defects in the apoptotic machinery are associated with the development of autoimmune and neoplastic diseases. Fas is a major trigger for apoptosis, especially in activated immune cells. Thus, the 
a

Control

Non induced

5h FasL

anti-v6 Ab

+ 5h FasL
Ju CD44s
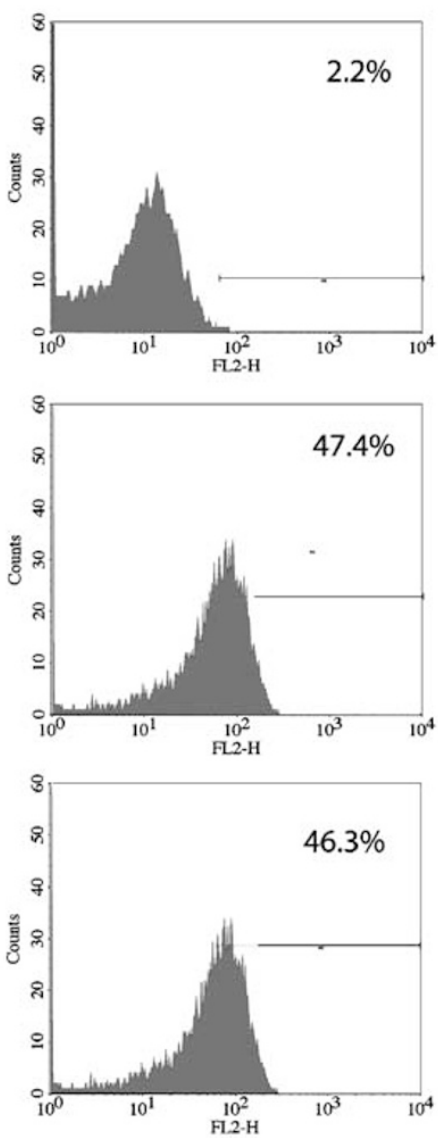

Ju CD44v6
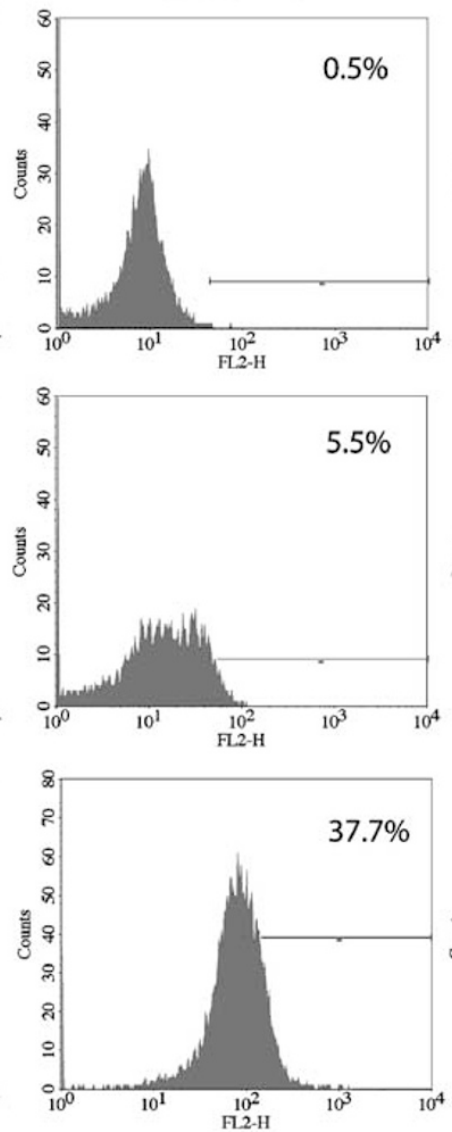

Ju CD44v6-10
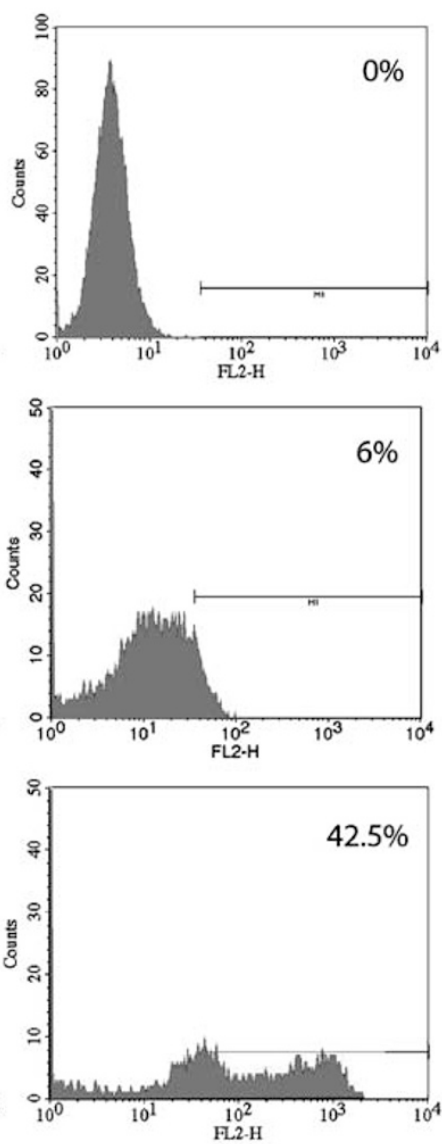

p85 PARP

b

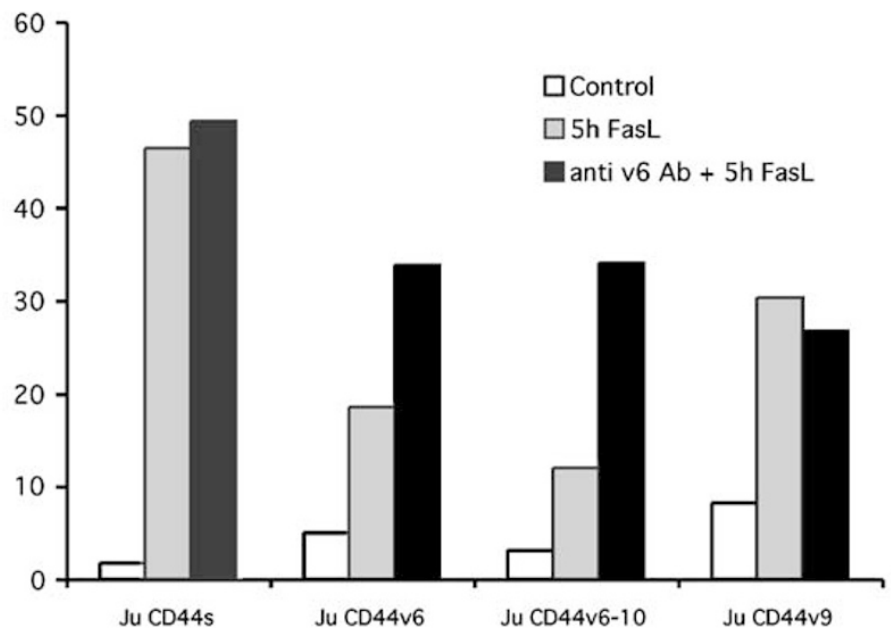

Figure 6 Interference with CD44v6 could induce susceptibility to apoptosis of CD44v6 ${ }^{+}$cells. (a) Upper panels: Jurkat CD44s, Jurkat CD44v6 and Jurkat CD44v6-10 untreated cells. Middle panels: Jurkat CD44s, Jurkat CD44v6 and Jurkat CD44v6-10 treated with FasL for $5 \mathrm{~h}$. Lower panels: Jurkat CD44s, Jurkat CD44v6 and Jurkat CD44v6-10 preincubated for $2 \mathrm{~h}$ with anti-CD44v6 antibody, followed by $5 \mathrm{~h}$ incubation with FasL. The numbers in the quadrants represent the percentage of apoptotic cells obtained in one experiment representative of three. The percentage of apoptotic cells was evaluated by measuring PARP cleavage. The bar is limiting the living cells on the left according to the control. (b) Jurkat CD44s, Jurkat CD44v6 and Jurkat CD44v6-10 untreated, treated with FasL for $5 \mathrm{~h}$ or preincubated for $2 \mathrm{~h}$ with antiCD44v6 antibody, then treated with FasL for $5 \mathrm{~h}$ were analyzed in hypotonic buffer. The percentage of apoptotic cells was evaluated by measuring loss of PI staining (hypodiploid DNA = subG1 apoptotic population). Values are given for one experiment representative of three 
blockade of Fas inhibits an important apoptotic pathway which is essential to maintain a proliferation-apoptosis equilibrium and immune homeostasis. ${ }^{30}$ It is well known that cell adhesion molecules such as the hyaluronan receptor CD44 play a critical role in tumor progression (reviewed by Günthert et $a .^{12}$ ).

We were interested to find out whether the correlation between poor prognosis in leukemia and lymphoma and presence of CD44v may be due to resistance to apoptosis. In a colitis model it was observed that mice lacking CD44v6/v7 showed increased apoptosis and consequently recovered from the life-threatening disease. ${ }^{22}$ In the present study we demonstrate that CD44v isoforms, which differ from CD44s only in the extracellular domain, confer resistance to apoptosis by colocalization and interaction with the death receptor Fas. Importantly, we have been able to narrow down the variant region responsible for this resistance to apoptosis to CD44v6 and v9, which were sufficient to protect T leukemia and plasmacytoma cells from programmed cell death. We have shown that CD44v6 and v9 colocalize and interact with Fas in the presence or the absence of FasL. Based on these findings, we propose a model in which CD44v interacts extracellularly with Fas, preventing (FasL binding and consequently) Fas death signaling (Figure 7).

More specifically, we suggest that the extracellular variant region of CD44 sequesters Fas and would hence prevent its trimerization, which is a necessary initial step to FasL binding and Fas signaling. ${ }^{31}$ This may concern binding of CD44v to the first contact sites for Fas trimerization, the preligand assembly domain (PLAD). ${ }^{32}$ Therefore, these CD44v isoforms could conceivably function as prosurvival molecules by binding to and sequestering the Fas death receptor. We are postulating this mechanism to be responsible for the apoptosis resistance, as seen in many studies on autoimmune diseases or human cancer, in which CD44v expression

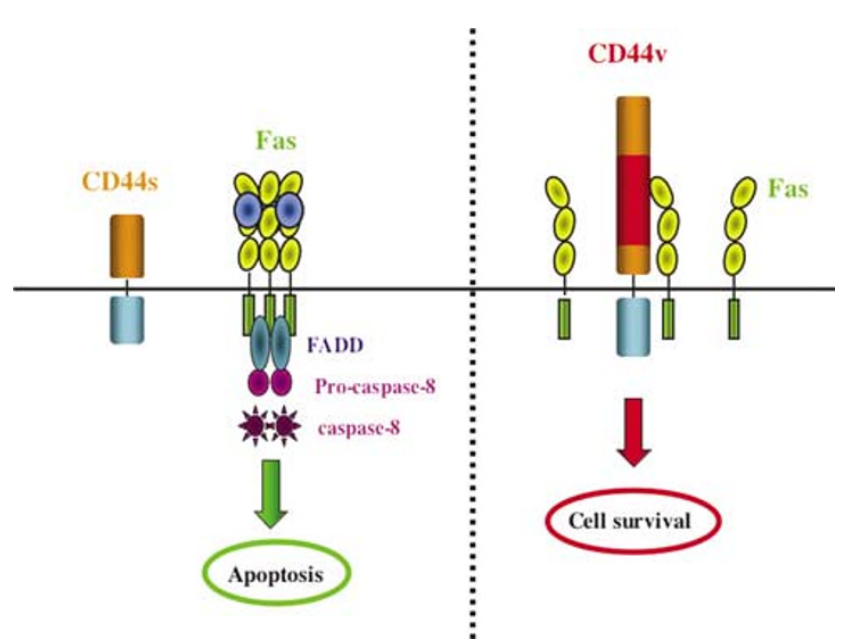

Figure 7 A model for Fas sequestration by CD44v. Molecular mechanism postulating how CD44v prevents apoptosis. We suggest that the variant region of CD44 may interact with the PLAD (pre-ligand assembly domain) of Fas and may thus prevent transiently its trimerization, which is a prerequisite for FasL binding. ${ }^{32}$ Hence, Fas remains inactivated and the death-signaling cascade does not take place is prevalent. ${ }^{3,19,22}$ Thus, when CD44v isoforms are aberrantly upregulated, Fas and CD44v remain associated and inhibit activation of Fas-mediated apoptosis. The structural features of CD44v isoforms may provide clues to their function with regard to Fas sequestration.

A similar mechanism of Fas sequestration, employing the tyrosine kinase receptor c-Met, has recently been described. ${ }^{33}$ In this study, the authors show that the interaction of the $\alpha$ chain of c-Met with Fas prevents its trimerization and binding to FasL and its further clustering. Thus, the association of c-Met and Fas provides a new mechanism of inhibition of death receptor-induced apoptosis. Interestingly, it has also been shown that c-Met and its ligand HGF interact with CD44v6 and this association is required for c-Met survival signaling.

The CD44v isoforms arise by alternative splicing of its mRNA (reviewed by Ponta et al. ${ }^{3}$ ). There is evidence that tumor promoters might control the choice of alternative splice sites, and such factors are upregulated during tumorigenesis. ${ }^{24,34}$ There are several indications that the transcripts of most genes encoding apoptotic regulators are subject to alternative splicing, which can result in the production of anti- or pro-apoptotic protein isoforms (reviewed by Shin and Manley ${ }^{34}$ ). This strategy may allow tumor and inflammatory cells to escape cell death and evade immune surveillance. Interestingly, our data demonstrate that anti-CD44v-specific antibodies can interfere with the CD44v-mediated apoptosis blockade and restore the potential of a cell to undergo apoptosis. Hence, interfering with the CD44 variant region by using specific tools could restore cell death capacity and resolve neoplastic and inflammatory lesions. This finding opens new strategies of therapeutic intervention in human cancers and autoimmune diseases that overexpress CD44V isoforms.

\section{Materials and Methods}

\section{Cell lines and generation of CD44 transfectants}

Jurkat cells were cotransfected by electroporation with $1.5 \mu \mathrm{g}$ of a neomycin resistance plasmid and $15 \mu \mathrm{g}$ of CD44s-, CD44v2-10-, CD44v3-10-, CD44v6-10-, CD44v8-10-, CD44v3-, CD44v6-, CD44v9or CD44v10-encoding DNA. Electroporation was performed by $250 \mathrm{~V}$ and $960 \mu \mathrm{F}$ with the micropulser (BioRad, Reinach, Switzerland). All constructs contain EGFP fused at the CD44 carboxy terminal end (Figure 1a).

Jurkat cells and the plasmacytoma cell lines RPMI-8226, IM-9 (EBVpositive lymphoblastoma), $\mathrm{NCl}-\mathrm{H} 929$ and $\mathrm{U} 266$ were obtained from the American Type Culture Collection (ATCC). The IL-6-dependent cell line XG-1 (XG-1 $\left.{ }^{+}\right)$was a kind gift of Dr. B Klein, Utrecht, The Netherlands. An IL-6-independent variant $\left(\mathrm{XG}-1^{-}\right)$was selected by limiting dilution of $X G$ $1^{+}$cells in the absence of IL-6. Cells were grown in SF-IMDM with $2.5 \%$ fetal calf serum at $37^{\circ} \mathrm{C}$ in a $5 \% \mathrm{CO}_{2}$ incubator and selected with $1 \mathrm{mg} / \mathrm{ml}$ of Geneticin G418 (Gibco, Basel, Switzerland).

For the plasmacytoma cell lines $10 \mu \mathrm{M}$ 2-ME and for the IL-6dependent XG-1 ${ }^{+}$cell line, $1.25 \mathrm{ng} / \mathrm{ml}$ IL-6 (Roche, Basel, Switzerland) were added to the culture medium.

Expression of CD44 isoforms and Fas was confirmed by flow cytometry with fluorescently labeled antibodies for panCD44- and CD44v-specific isoforms (Table 1). Cells with similar green fluorescence intensities were 
sorted on a MoFlo high-speed cell sorter (DakoCytomation, Zug, Switzerland). Transfected cells with comparable CD44 expression levels and comparable Fas expression levels were used for the apoptosis assays.

\section{Antibodies and reagents}

The antibodies used for Western blotting were: mouse monoclonal anti-human panCD44 (clone Hermes 3 was a kind gift of Dr. E Butcher, Stanford, CA, USA), rabbit polyclonal anti-human Fas (Immunokontact, Lugano, Switzerland), mouse monoclonal anti-human FADD (clone 1, Transduction Laboratories, Basel, Switzerland), mouse monoclonal antihuman Bcl-2 (clone C-2, St. Cruz Biotechnology) and mouse monoclonal anti-tubulin as control for equal loading (clone 236-10 501, Molecular Probes, Leiden, The Netherlands), followed by goat anti-mousehorseradish peroxidase (HRP) (Pierce) or goat anti-rabbit-HRP (Pierce). The signal was visualized by chemoluminescence with Super Signal Substrate (Pierce).

The blocking antibodies used for interfering with the variant region of CD44 were: mouse monoclonal anti-human CD44v6 (clone BBA 13, R\&D Systems, Wiesbaden-Nordenstadt, Germany; clone VFF18, Bender MedSystems, Vienna, Austria) and mouse monoclonal anti-human CD44v9, clone FW11.24. ${ }^{35}$

\section{Apoptosis induction}

Neuro-2A cells, producing recombinant mouse FasL, were grown as described. ${ }^{36}$ Jurkat transfectants $\left(5 \times 10^{5}\right.$ cells $\left./ \mathrm{ml}\right)$ were incubated with serial dilutions of Neuro-2A supernatant or with a mouse anti-human Fas IgM mAb (5-200 ng/ml) (clone 7C11, Immunotech, Marseille, France) for 1,3 or $6 \mathrm{~h}$ at $37^{\circ} \mathrm{C}$. For the plasmacytoma cell lines and the EBV-positive lymphoblastoma cell line, the time of incubation with Fas crosslinking antibody was extended to $24 \mathrm{~h}$.

The Jurkat transfectants were also induced to undergo non-Fasmediated apoptosis with different stimuli such as: UV light (10000 J), PMA $(0.2 \mu \mathrm{M})$ /ionomycin $(1 \mu \mathrm{g} / \mathrm{ml})$, heat shock $\left(1 \mathrm{~h}, 43^{\circ} \mathrm{C}\right)$ or $\gamma$-irradiation $(2.5$ and $10 \mathrm{~Gy}$ ). Apoptosis was evaluated after $48 \mathrm{~h}$ in culture by flow cytometry with AnnexinV/PI staining.

\section{Evaluation of apoptosis}

The cells, either Fas triggered or untreated, were evaluated for apoptosis by five different methods:

(1) AnnexinV/Pl: Cells were stained with annexinV conjugated to allophycocyanine (Alexis, Basel, Switzerland) and $5 \mu \mathrm{g} / \mathrm{ml} \mathrm{PI} \mathrm{(Sigma,}$ Buchs, Switzerland) for $10 \mathrm{~min}$ in the dark at room temperature. Percentage of apoptotic cells was defined as the percentage of cells that were positive for annexinV and PI staining. The percentage of apoptotic cells measured in the untreated or mouse lgM control cells was subtracted from the percentage of apoptotic cells measured in the induced cells. Apoptosis was evaluated by flow cytometry (FACS Calibur, Becton Dickinson, Basel, Switzerland).

(2) p85 PARP: Cells were fixed with $4 \%$ paraformaldehyde (PFA in PBS) for $20 \mathrm{~min}$ at room temperature, permeabilized for $10 \mathrm{~min}$ at room temperature with PBS containing $0.1 \%$ saponin and $0.09 \%$ sodium azide, and stained with a rabbit anti-p85 PARP antibody conjugated to PE (Promega, Wallisellen, Switzerland). Percentage of apoptotic cells was evaluated with flow cytometry.

(3) Hypodiploid DNA: Cells were incubated overnight, at $4^{\circ} \mathrm{C}$, in the dark in a hypotonic DNA-binding buffer containing $0.1 \%$ sodium citrate,
$0.1 \%$ Triton X-100 and $50 \mu \mathrm{g} / \mathrm{ml}$ PI in PBS. Percentages of apoptosis of untreated and FasL-treated cells were compared by flow cytometric analysis. Apoptosis was evaluated by measuring loss of $\mathrm{PI}$ staining (corresponding to the hypodiploid DNA population, also called subG1 apoptotic population) in the FL3 channel. ${ }^{25}$

(4) The data obtained from these three methods were analyzed with the CellQuest program (Becton Dickinson).

(5) Caspase-3 activity assay (Roche, Basel, Switzerland): Cells were prepared and processed according to the manufacturer's instructions.

(6) SDS-PAGE and Western blotting. Jurkat cells untreated and treated for 30 or 120 min with 7 C11 were collected, lysed in RIPA buffer $(150 \mathrm{mM}$ $\mathrm{NaCl}, 10 \mathrm{mM}$ Tris- $\mathrm{HCl} \mathrm{pH} 7.2,0.1 \%$ SDS, 1\% Triton X-100, 1\% deoxycholate, $5 \mathrm{mM}$ EDTA). Extracts were resuspended in $2 \times$ SDS sample buffer (100 mM Tris-HCl pH 6.8, 25\% glycerol, 2\% SDS, 0.1\% bromophenol blue, $10 \% 2-\mathrm{ME}$ ), denatured at $96^{\circ} \mathrm{C}$ for $5 \mathrm{~min}$ and separated on $10 \%$ SDS polyacrylamide gels. Proteins were transferred to polyvinylidene fluoride membranes (Schleicher \& Schuell, Dassel, Germany) and blocked for $1 \mathrm{~h}$ at room temperature in PBS with $3 \%$ Top Block (Juro, Luzern, Switzerland). PARP cleavage was detected with a mouse anti-PARP antibody (PharMingen, Basel, Switzerland) followed by a HRP-conjugated goat anti-mouse antibody (Pierce, Basel, Switzerland). Detection was performed by chemoluminescence with Super Signal Substrate (Pierce).

\section{Nitrogen cavitation bomb ${ }^{29}$}

Cells $\left(10^{8}\right)$ were collected, washed with PBS, centrifuged for $5 \mathrm{~min}$ at $1300 \mathrm{rpm}$ and incubated for $30 \mathrm{~min}$ at $4^{\circ} \mathrm{C}$ on a rotating wheel with magnetic beads coated with a secondary goat anti-mouse IgG antibody (Dynal, Hamburg, Germany). The beads were consecutively coated with a primary anti-CD95 antibody (clone ANC 95.1/5E2, Ancell, Sissach, Switzerland) or anti-panCD44 antibody (clone Hermes 3), according to the manufacturer's protocol. The cells coated with beads were then treated with FasL for $10 \mathrm{~min}$ at $37^{\circ} \mathrm{C}$ or left untreated, washed with ice-cold $\mathrm{H}$-Buffer (250 mM sucrose, $10 \mathrm{mM}$ Na-Hepes pH 7.2, $2 \mathrm{mM} \mathrm{MgCl}_{2}, 10 \mathrm{mM}$ $\mathrm{NaF}, 1 \mathrm{mM}$ sodium vanadate) and retrieved with a magnetic device (Dynal) several times. The cells coated with the beads were then surface crosslinked for $2 \mathrm{~h}$ at $4^{\circ} \mathrm{C}$ in a rotating wheel with $1 \mathrm{mg} / \mathrm{ml}$ DTSSP (Pierce). Crosslinking was stopped by incubating the cells with $20 \mathrm{mM}$ Tris- $\mathrm{HCl}$ $\mathrm{pH} 7.5$ for $15 \mathrm{~min}$ on ice. Cells were intensively washed in H-Buffer, resuspended in $\mathrm{H}$-Buffer $+(\mathrm{H}$-Buffer with $6.6 \mu \mathrm{M}$ pervanadate and one mini tablet of a protease inhibitor cocktail (Roche, Penzberg, Germany) for $10 \mathrm{ml}$ of solution. The number of cells coated with beads was counted under the microscope and approximately $4 \times 10^{6}$ cells per sample were disrupted in a nitrogen cavitation bomb at $-196^{\circ} \mathrm{C}$ and $600 \mathrm{psi}$ (pounds per square in ch). After disruption of the membranes, the samples were washed and retrieved four times and finally resuspended in $2 \times$ SDS sample buffer. For further Western blotting analysis, the extracts were processed as described above and immunoblotted with rabbit polyclonal anti-CD95 antibody (Immunokontact) or mouse monoclonal anti-panCD44 antibody (Hermes 3 ) respectively, followed by goat anti-rabbit-HRP (Pierce) and goat anti-mouse-HRP (Pierce). The signals were visualized by chemoluminescence (Pierce).

\section{M $\beta C D$ treatment}

Cells were exposed to $10 \mathrm{mM} \mathrm{M} \beta C D$ (Sigma) for 20 or $40 \mathrm{~min}$ before apoptosis induction for $5 \mathrm{~h}$ with FasL. This dose is sufficient to selectively extract the cholesterol from the plasma membrane and to disrupt lipid 
rafts. Apoptosis was evaluated by flow cytometry by measuring the sub $\mathrm{G} 1$ population. ${ }^{25}$

\section{Confocal microscopy}

For confocal analysis Jurkat CD44s, Jurkat CD44v2-10, Jurkat CD44v6 and Jurkat CD44v9 cells, untreated or treated with FasL for $1 \mathrm{~h}$, were stained with mouse monoclonal anti-human panCD44 (Hermes 3), followed by secondary goat anti-mouse IgG conjugated with Cy2 (Amersham). Cells were also stained with an anti-human Fas biotinylated antibody (clone ANC 95.1/5E2 Ancell, Basel, Switzerland), followed by a secondary reaction with streptavidin-Texas Red (SA-TxR) (Southern Biotechnology, Reinach, Switzerland). After staining, the cells were fixed for $20 \mathrm{~min}$ at room temperature with $2 \%$ PFA, spun onto slides (Cytospin) and mounted in Mowiol. Confocal image stacks were recorded on a Leica TCS 4D operating in the simultaneous acquisition mode. Specimens stained only with one fluorochrome were examined and demonstrated that the setup did not result in crosstalk between channels. Images were analyzed for colocalization using the Imaris software package (Bitplane AG, Zürich, Switzerland) and applying a threshold well above the noise level. ${ }^{37}$ The data were statistically analyzed with the Wilcoxon signed-rank test.

\section{Blocking of apoptosis}

Jurkat and XG-1 transfectants were preincubated for $2 \mathrm{~h}$ at $37^{\circ} \mathrm{C}$ with mouse anti-human-specific CD44v antibodies (see description in antibodies and reagents), followed by treatment with FasL for $5 \mathrm{~h}$. Cells were prepared either for analysis of hypodiploid DNA ${ }^{25}$ or intracellular stained with an anti-p85 PARP antibody conjugated with PE. Percentages of apoptosis of untreated, FasL treated and antibody plus FasL-treated cells were compared by flow cytometric analysis (Becton Dickinson).

Expression of CD44s, v3, v6, v7, v9, v10 and Fas on plasmacytoma cell lines and an EBV-positive lymphoblastoma cell line, CD44-transfected XG-1 plasmacytoma cell lines and CD44-transfected Jurkat (Ju) cell lines, measured by FACS. Plasmacytoma cell lines U266 and XG-1 ${ }^{+}$are IL- 6 dependent.

\section{Acknowledgements}

We express our thanks to Drs. Thomas Harder (Oxford, UK) for introducing the cavitation bomb method and to Adriano Fontana (University Hospital, Zürich, Switzerland) for kindly providing us with the Neuro-2A cells expressing murine FasL. We also thank Drs. A Rolink, P Erb, B Wittig, H Hirsch, V Brondani, I Raineri, D Benjamin and J Ji for critical comments on the manuscript. We are grateful to Britt Johansson for making all the transfectants and for the initial experiments showing that CD44v blocks FAS-mediated apoptosis as well as $\mathrm{H}$ Kohler (Friedrich Miescher Institute, Basel) for sorting the transfectants. M Wernli, V Crotet, J Samaridis, A Glaser-Ruhm and E Kump for technical advice and assistance. Dr. P Marbet for helpful advice concerning the immunofluorescence preparations for confocal microscopy. This work is supported by a Grant from the Swiss Science Foundation (3100-067084.01) and the Swiss Cancer League (OCS 1265-08-2002).

\section{References}

1. Aruffo A, Stamenkovic I, Melnick M, Underhill C and Seed B (1990) CD44 is the principal cell surface receptor for hyaluronate. Cell 61: 1303-1313
2. Günthert U (1993) CD44: a multitude of isoforms with diverse functions. Curr. Top Microbiol. Immunol. 184: 47-63

3. Ponta H, Sherman L and Herrlich PA (2003) CD44: from adhesion molecules to signalling regulators. Nat. Rev. Mol. Cell Biol. 4: 33-45

4. Nandi A, Estess P and Siegelman M (2004) Bimolecular complex between rolling and firm adhesion receptors required for cell arrest; CD44 association with VLA-4 in T cell extravasation. Immunity 20: 455-465

5. Orian-Rousseau V, Chen L, Sleeman JP, Herrlich P and Ponta H (2002) CD44: is required for two consecutive steps in HGF/c-Met signaling. Genes Dev. 16: 3074-3086

6. Yu WH, Woessner Jr JF, McNeish JD and Stamenkovic I (2002) CD44 anchors the assembly of matrilysin/MMP-7 with heparin-binding epidermal growth factor precursor and ErbB4 and regulates female reproductive organ remodeling. Genes Dev. 16: 307-323

7. Denhardt DT, Noda M, O'Regan AW, Pavlin D and Berman JS (2001) Osteopontin as a means to cope with environmental insults: regulation of inflammation, tissue remodeling, and cell survival. J. Clin. Invest. 107: 1055-1061

8. Hibino S, Shibuya M, Engbring JA, Mochizuki M, Nomizu M and Kleinman HK (2004) Identification of an active site on the laminin alpha5 chain globular domain that binds to CD44 and inhibits malignancy. Cancer Res. 64: 4810-4816

9. Herrlich $P$, Sleeman J, Wainwright $D$, König $H$, Sherman L, Hilberg $F$ and Ponta H (1998) How tumor cells make use of CD44. Cell Adhes. Commun. 6: 141-147

10. Wittig BM, Stallmach A, Zeitz M and Günthert $U$ (2002) Functional involvement of CD44 variant 7 in gut immune response. Pathobiology 70: 184-189

11. Günthert U, Hofmann M, Rudy W, Reber S, Zöller M, Haussmann I, Matzku S, Wenzel A, Ponta H and Herrlich P (1991) A new variant of glycoprotein CD44 confers metastatic potential to rat carcinoma cells. Cell 65: 13-24

12. Günthert U, Stauder R, Mayer B, Terpe H-J, Finke L and Friedrichs K (1995) Are CD44 variant isoforms involved in human tumour progression? Cancer Surv. 24: 19-42

13. van Driel M, Günthert U, Stauder R, Joling $P$, Lokhorst HM and Bloem AC (1998) CD44 isoforms distinguish between bone marrow plasma cells from normal individuals and patients with multiple myeloma at different stages of disease. Leukemia 12: 1821-1828

14. Eisterer W, Bechter O, Hilbe W, van Driel M, Lokhorst HM, Thaler J, Bloem AC, Günthert $U$ and Stauder $R$ (2001) CD44 isoforms are differentially regulated in plasma cell dycrasias and CD44v9 represents a new independent prognostic parameter in multiple myeloma. Leuk. Res. 25: 1051-1057

15. Stauder R, Eisterer W, Thaler J and Günthert U (1995) CD44 variant isoforms in non-Hodgkin's lymphoma: a new independent prognostic factor. Blood 85: 2885-2899

16. Legras S, Günthert U, Stauder R, Curt F, Oliferenko S, Kluin-Nelemans HC, Marie JP, Proctor S, Jasmin C and Smadja-Joffe F (1998) A strong expression of CD44-6v correlates with shorter survival of patients with acute myeloid leukemia. Blood 91: 3401-3413

17. Charrad R, Gadhoum Z, Qi J, Glachant A, Allouche M, Jasmin C, Chomienne C and Smadja-Joffe $F$ (2002) Effects of anti-CD44 monoclonal antibodies on differentiation and apoptosis of human myeloid leukemia cell lines. Blood 99: 290-299

18. Günthert A, Sträter J, von Reyher U, Henne C, Joos S, Koretz K, Moldenhauer G, Krammer PH and Möller P (1996) Early detachment of colon carcinoma cells during CD95 (APO-1/Fas)-mediated apoptosis. I. De-adhesion from hyaluronate by shedding of CD44. J. Cell Biol. 134: 1089-1096

19. Günthert $U$ and Johansson B (2001) CD44 - a protein family involved in autoimmune diseases and apoptosis. Immunologist 8: 106-109

20. Laman JD, Maassen CB, Schellekens MM, Visser L, Kap M, de Jong E, van Puijenbroek M, van Stipdonk MJ, van Meurs M, Schwärzler $C$ and Günthert $U$ (1998) Therapy with antibodies against CD40L (CD154) and CD44-variant isoforms reduces experimental autoimmune encephalomyelitis induced by a proteolipid protein peptide. Mult. Scler. 4: 147-153

21. Wittig BM, Schwärzler C, Föhr N, Günthert U and Zöller M (1998) Curative treatment of an experimentally induced colitis by a CD44 variant v7 specific antibody. J. Immunol. 161: 1069-1073

22. Wittig BM, Johansson B, Zöller M, Schwärzler C and Günthert U (2000) Abrogation of experimental colitis correlates with increased apoptosis in mice deficient for CD44 variant exon 7 (CD44v7). J. Exp. Med. 191: 2053-2064 
23. Ast G (2004) How did alternative splicing evolve? Nat. Rev. Genet. 5: 773-782

24. Weg-Remers S, Ponta H, Herrlich P and König H (2001) Regulation of alternative pre-mRNA splicing by the ERK MAP-kinase pathway. EMBO J. 20: 4194-4203

25. Nicoletti I, Migliorati G, Pagliacci MC, Grignani F and Riccardi C (1991) A rapid and simple method for measuring thymocyte apoptosis by propidium iodide staining and flow cytometry. J. Immunol. Methods. 139: 271-279

26. Bennett KL, Jackson DG, Simon JC, Tanczos E, Peach R, Modrell B, Stamenkovic I, Plowman G and Aruffo A (1995) CD44 isoforms containing exon V3 are responsible for the presentation of heparin-binding growth factor. J. Cell Biol. 128: 687-698

27. Oliferenko S, Paiha K, Harder T, Gerke V, Schwärzler C, Schwarz H, Beug H, Günthert U and Huber LA (1999) Analysis of CD44 containing lipid rafts: recruitment of annexin II and stabilization by the actin cytoskeleton. J. Cell Biol. 146: 843-854

28. Scheel-Toellner D, Wang K, Singh R, Majeed S, Raza K, Curnow SJ, Salmon $M$ and Lord JM (2002) The death-inducing signalling complex is recruited to lipid rafts in Fas-induced apoptosis. Biochem. Biophys. Res. Commun. 297: 876-879

29. Harder T and Kuhn M (2001) Immunoisolation of TCR signaling complexes from Jurkat T leukemic cells. Sci. STKE. 71: PL1
30. Opferman $\mathrm{J}$ and Korsmeyer S (2003) Apoptosis in the development and maintenance of the immune system. Nat. Immunol. 4: 410-415

31. Siegel RM, Chan FK, Chun HJ and Lenardo MJ (2000) The multifaceted role of Fas signaling in immune cell homeostasis and autoimmunity. Nat. Immunol. 1: 469-474

32. Chan FK, Chun HJ, Zheng L, Siegel R, Bui K and Lenardo MJ (2000) A domain in TNF receptors that mediates ligand-independent receptor assembly and signaling. Science 288: 2351-2354

33. Wang X, DeFrances MC, Dai $Y$, Pediaditakis $P$, Johnson C, Bell A, Michalopoulos GK and Zarnegar R (2002) A mechanism of cell survival: sequestration of Fas by the HGF receptor Met. Mol. Cell 9: 411-421

34. Shin $C$ and Manley $J L$ (2004) Cell signalling and the control of pre-mRNA splicing. Nat. Rev. Mol. Cell Biol. 5: 727-738

35. Mackay CR, Terpe H-J, Stauder R, Marston WL, Stark H and Günthert U (1994) Expression and modulation of CD44 variant isoforms in humans. J. Cell Biol. 124: 71-82

36. Rensing-Ehl A, Frei K, Flury R, Matiba B, Mariani SM, Weller M, Aebischer P, Krammer PH and Fontana A (1995) Local Fas/APO-1 (CD95) ligand-mediated tumor cell killing in vivo. Eur. J. Immunol. 25: 2253-2258

37. Landmann $L$ (2002) Deconvolution improves colocalization analysis of multiple fluorochromes in $3 \mathrm{D}$ confocal data sets more than filtering techniques. J. Microsc. 208: 134-147

Supplementary Information accompanies the paper on the Cell Death and Differentiation website (http://www.nature.com/cdd) 